Revista de Ciencias Sociales - Número 62 (2013) - Páginas 13-37

La extinta facultad de investigación de la Suprema Corte de Justicia de la Nación de México

\title{
LA EXTINTA FACULTAD DE INVESTIGACIÓN DE LA SUPREMA CORTE DE JUSTICIA DE LA NACIÓN EN MÉXICO
}

\author{
THE FORMER RESEARCH FACULTY OF THE \\ MEXICAN SUPREM COURT'S
}

\author{
MARCO ANTONIO RODRÍGUEZ ESCOBEDO* \\ Instituto de Investigaciones Parlamentarias del \\ Congreso del Estado de Tamaulipas \\ México \\ marcoaro@ucm.es
}

\section{Resumen}

El presente artículo trata de analizar uno de los temas más trascendentes de la reforma constitucional en materia de derechos humanos de junio de 2011, la relativa al artículo 97, por medio de la cual se retira la facultad de investigación de la Suprema Corte de Justicia de la Nación establecida en el segundo párrafo, para transferírsela a la Comisión Nacional de los Derechos Humanos en el artículo 102 constitucional y además responder a la interrogante ¿fue acertada o no la trasferencia de dicha función estatal?

* Maestro en Derecho Constitucional por la Universidad Autónoma de

Tamaulipas, México y cursando el Máster en Derecho Parlamentario, Elecciones y Estudios Legislativos (promoción 2012-2013) impartido por el Instituto de Derecho Parlamentario de la Facultad de Derecho de la Universidad Complutense de Madrid. Artículo recibido el 27 de febrero de 2013 y aceptado el 3 de abril de 2013.

Revista de Ciencias Sociales - Número 62 (2013) - Universidad de Valparáíso - ISSN 0716-7725-Valparaíso, Chile 


\title{
Palabras claves
}

Facultad de investigación, derechos humanos, Suprema Corte de Justicia, transferencia constitucional.

\begin{abstract}
This article attempts to analyze one of the most significant issues of constitutional reform on human rights in June 2011, on article 97, by means of which the faculty of investigation is removed from the Supreme Court of Justice Nation established in the second paragraph, to transfer it to the National Commission of Human Rights in the constitutional article 102 and also answer the question, Was it a good choice or not the transfer of the state function?
\end{abstract}

Keywords

Research faculty, human rights, Supreme Court, constitutional transfer.

\section{Introducción}

El 10 de junio del 2011, se publicó en el Diario Oficial de la Federación, el Decreto de reforma constitucional en materia de Derechos Humanos.

Dicha reforma al igual que la de amparo y la de justicia penal, vistas en conjunto, representan la renovación más intensa de las labores jurisdiccionales que el país haya atestiguado en su historia moderna ${ }^{1}$.

La reforma constitucional en materia de derechos humanos incluye modificaciones a la denominación del Capítulo I del Título Primero y a los artículos $1^{\circ}, 3^{\circ}, 11,15,18,29,33,89,97,102$ y 105 , con las cuales se hace un reconocimiento a los derechos humanos como realidades inherentes a la persona y se incorporan constitucionalmente los derechos reconocidos en los tratados internacionales de los que

1. Palabras del Señor Ministro Presidente de la Suprema Corte de Justicia de la

Nación Juan N. Silva Meza, en la Sesión Pública Solemne del Pleno de la Suprema Corte de Justicia de la Nación con motivo de la entrada en vigor de la Décima Época del Semanario Judicial de la Federación, celebrada el martes 4 de octubre de 2011.

Facultad de Derecho y Ciencias Sociales - Universidad de Valparaíso - Chile 
México es parte. La transcendencia de este hecho radica en el fortalecimiento del texto constitucional como instrumento protector y garante de los derechos humanos.

Uno de los temas más trascendentes, es la relativa al artículo 97, en ella se retira la facultad de investigación de la Suprema Corte de Justicia de la Nación establecida en el segundo párrafo, para transferírsela a la Comisión Nacional de los Derechos Humanos en el artículo 102 constitucional. La anterior es una atribución constitucional que no se suprime sino que, se reasigna a otro Órgano del Estado pero de naturaleza autónoma.

En el presente ensayo se pretende responder la siguiente incógnita, ¿̇Fue acertada la transferencia de la función de investigación de la Suprema Corte a la Comisión Nacional de los Derechos Humanos?, a continuación la reflexión sobre el tema.

\section{Antecedentes de la facultad de investigación de la Suprema Corte de Justicia de la Nación, ahora de la Comisión Nacional de los Derechos Humanos}

Sin duda, para desentrañar el verdadero sentido y razón de ser de alguna institución o figura jurídica, hay que acudir a las causas que motivaron su creación, es decir, a esas razones sociales, económicas, políticas, jurídicas, etc., que pugnan por la implementación de determinadas instancias o mecanismos de defensa de sus derechos de los ciudadanos. Pues bien, respecto a las razones por las que se implementó la Facultad de Investigación de la Suprema Corte de Justicia de la Nación en el texto original de la Constitución Política de 1917, son bastante imprecisas, pues no existe un antecedente contundente en nuestro país ni en ningún otro, que nos lleve a afirmar categóricamente los motivos por los que este instrumento procesal fue implementado en la Ley Fundamental.

Algunos estudiosos de gran respeto en la materia constitucional, han señalado las supuestas razones de ser de este instrumento procesal, por lo que nos resulta bastante ilustrativo reproducir en el presente documento, sus opiniones:

Revista de Ciencias Sociales - Número 62 (2013) - Universidad de Valparáíso - ISSN 0716-7725-Valparaíso, Chile 
El Doctor Jorge Carpizo, en su obra Estudios Constitucionales, citando la tesis profesional que sobre este tema elaboró Félix Valencia Valladolid, refiere que los hechos acontecidos en Veracruz en 1879, en los que el gobernador Mier y Terán, ordenó el fusilamiento de varias personas detenidas, acontecimientos que acapararon la atención de los medios de comunicación escritos, a tal magnitud que motivaron que la Suprema Corte de Justicia de la Nación ordenara la averiguación de los hechos referidos, creándose con ello, el antecedente directo del modificado artículo 97 constitucional.

Por su parte, Pablo Enrique Reyes Reyes, citado por Fix Zamudio en su obra Estudio de la Defensa de la Constitución en el Ordenamiento Mexicano, sostiene que no deben tomarse los acontecimientos señalados como el antecedente directo de la facultad de investigación de la Suprema Corte, sino las convenciones de la Haya de 1899 y 1907, sobre el Arreglo Pacífico de Conflictos Internacionales, en donde se contienen instrumentos para la solución de conflictos, entre otros, la formación de comisiones de investigación de carácter internacional.

A pesar de lo apuntado y "los meritorios esfuerzos por encontrar una influencia directa de la institución establecida por el tercer párrafo del artículo 97 constitucional aprobado por el Constituyente de Querétaro tomó en consideración los mencionados instrumentos internacionales, y tampoco se ha afirmado que dicha Asamblea se hubiera apoyado directamente en los hechos de junio de 1979”2.

\section{Medios de control constitucional}

La Constitución Política de los Estados Unidos Mexicanos tiene el carácter de suprema, lo que en términos de la doctrina constitucional significa, que no existirá ninguna ley con rango superior a ella. No obstante ello, habrá casos en que los gobernantes realicen actos vulnerando el contenido de la Ley Fundamental sin importarles en lo más mínimo las limitaciones que en ella se establece para el ejercicio

2. FIX ZAMUDIO, Héctor: Estudio de la Defensa de la Constitución en el Ordenamiento Mexicano (segunda edición). editorial Porrúa, México, 2005. Pág. 249.

Facultad de Derecho y Ciencias Sociales - Universidad de Valparaíso - Chile 
del poder, es precisamente esta razón, la que motivó al constituyente original y el permanente, para establecer una serie de mecanismos procesales - garantías constituciones - algunos jurisdiccionales y otros no, que pueden activarse cuando "el orden constitucional es desconocido o violado con el objeto de restaurarlo" . Estos medios de control constitucional se encuentran dispersos en el articulado de la Constitución Federal, y se pueden clasificar como jurisdiccionales y no jurisdiccionales.

\section{a) jurisdiccionales}

\begin{tabular}{|c|c|c|}
\hline $\begin{array}{c}\text { Jurisdiccionales } \\
\text { (de naturaleza vinculatoria) }\end{array}$ & Ley Reglamentaria & $\begin{array}{l}\text { Objeto del instrumento } \\
\text { procesal }\end{array}$ \\
\hline 1. El Juicio de Amparo. & $\begin{array}{l}\text { Ley de Amparo, } \\
\text { reglamentaria de los } \\
\text { artículos } 103 \text { y } 107 \\
\text { de la Constitución. }\end{array}$ & $\begin{array}{c}\text { Medio de defensa por } \\
\text { excelencia ahora de los } \\
\text { derechos humanos } \\
\text { (contenidos tanto en la } \\
\text { Constitución como en los } \\
\text { Tratados Internacionales). }\end{array}$ \\
\hline $\begin{array}{l}\text { 2. La Acción de } \\
\text { Inconstitucionales. }\end{array}$ & $\begin{array}{l}\text { Ley reglamentaria del } \\
\text { artículo } 105 \text { de la } \\
\text { Constitución. }\end{array}$ & $\begin{array}{l}\text { Plantear la contradicción } \\
\text { de una norma de carácter } \\
\text { general y la constitución. }\end{array}$ \\
\hline $\begin{array}{l}\text { 3. La Controversia } \\
\text { Constitucional. }\end{array}$ & $\begin{array}{l}\text { Ley reglamentaria del } \\
\text { artículo } 105 \text { de la } \\
\text { Constitución. }\end{array}$ & $\begin{array}{c}\text { Solución de conflictos } \\
\text { entre los poderes de la } \\
\text { unión. }\end{array}$ \\
\hline $\begin{array}{l}\text { 4. Juicio de Revisión } \\
\text { Constitucional Electoral. }\end{array}$ & $\begin{array}{l}\text { Ley General del Sistema } \\
\text { de Medios de } \\
\text { Impugnación en } \\
\text { Materia Electoral, } \\
\text { reglamentaria de los } \\
\text { artículos } 41,60 \text { y } 99 \\
\text { de la Constitución. }\end{array}$ & \begin{tabular}{|c} 
Garantizar el respeto \\
irrestricto a las \\
disposiciones \\
constitucionales y legales \\
en los actos y resoluciones \\
de las autoridades de las \\
entidades federativas en la \\
organización y calificación \\
de las elecciones.
\end{tabular} \\
\hline
\end{tabular}

3. FIX ZAMUDIO, Héctor y otro: Derecho Constitucional Mexicano y Comparado (quinta edición). Editorial porrúa, México, 2007. Pág. 183.

Revista de Ciencias Sociales - Número 62 (2013) - Universidad de Valparáíso - ISSN 0716-7725-Valparaíso, Chile 


\begin{tabular}{|c|c|c|}
\hline $\begin{array}{c}\text { 5. El Juicio para la protección } \\
\text { de los Derechos Político } \\
\text { Electorales del Ciudadano. }\end{array}$ & $\begin{array}{c}\text { Ley General del } \\
\text { Sistema de Medios de } \\
\text { Impugnación en } \\
\text { Materia Electoral, } \\
\text { reglamentaria de los } \\
\text { artículos } 41,60 \text { y } 99\end{array}$ & $\begin{array}{c}\text { Restituir al ciudadano } \\
\text { en el goce del derecho } \\
\text { político presuntamente } \\
\text { de la Constitución. }\end{array}$ \\
& \\
\hline
\end{tabular}

\section{b) no jurisdiccionales}

\begin{tabular}{|c|c|c|}
\hline No jurisdiccionales & Ley Reglamentaria & $\begin{array}{l}\text { Objeto del instrumento } \\
\text { procesal }\end{array}$ \\
\hline 6. Juicio Político. & $\begin{array}{c}\text { Ley Federal de } \\
\text { Responsabilidades } \\
\text { Administrativas de los } \\
\text { Servidores Públicos. }\end{array}$ & $\begin{array}{l}\text { Sancionar a los servidores } \\
\text { públicos cuando en el } \\
\text { ejercicio de sus funciones } \\
\text { incurran en actos u } \\
\text { omisiones que redundan } \\
\text { en perjuicio de los } \\
\text { intereses públicos } \\
\text { fundamentales o su } \\
\text { buen despacho. }\end{array}$ \\
\hline $\begin{array}{l}\text { 7. Las Recomendaciones de las } \\
\text { Comisiones Protectoras de los } \\
\text { Derechos Humanos. (De } \\
\text { naturaleza no vinculatoria). }\end{array}$ & $\begin{array}{c}\text { Ley de la Comisión } \\
\text { Nacional de Derechos } \\
\text { Humanos. }\end{array}$ & $\begin{array}{l}\text { Esencialmente tiene como } \\
\text { fin la protección, } \\
\text { observancia, promoción, } \\
\text { estudio y divulgación } \\
\text { de los derechos humanos } \\
\text { que ampara el orden } \\
\text { jurídico mexicano. }\end{array}$ \\
\hline $\begin{array}{c}\text { 8. La Facultad de } \\
\text { Investigación antes de la } \\
\text { Suprema Corte de Justicia } \\
\text { de la Nación, ahora de la } \\
\text { Comisión Nacional de los } \\
\text { Derechos Humanos (De } \\
\text { naturaleza no vinculatoria). }\end{array}$ & $\begin{array}{l}\text { No existe disposición } \\
\text { reglamentaria. }\end{array}$ & $\begin{array}{c}\text { Protección a la violación } \\
\text { grave y generalizada a los } \\
\text { derechos humanos. }\end{array}$ \\
\hline
\end{tabular}

Facultad de Derecho y Ciencias Sociales - Universidad de Valparaíso - Chile 
Los anteriores instrumentos constitucionales, creados para la defensa y salvaguarda de las normas supremas, la gran mayoría de ellos no aparecieron en la redacción original de la constitución de 1917, sino que se han ido implementando de acuerdo a la evolución política y jurídica de la sociedad mexicana, es de destacarse, que la Facultad de Investigación antes de la Suprema Corte ahora de la Comisión Nacional de los Derechos Humanos y el Juicio de Amparo, se encuentran contenidos en la Carta Magna desde su creación. Por lo que nos resulta interesante avocarnos al estudio y eficacia que tuvo este medio de control constitucional durante los poco más de cien años de vigencia.

\title{
4. Naturaleza de la facultad establecida en artículo 97 constitucional
}

El Constituyente Original de 1916-1917, introdujo al sistema constitucional mexicano un innovador medio de control constitucional, que consistía en facultar a la Suprema Corte de Justicia de la Nación para investigar hechos que constituyeran violación a alguna garantía individual o al voto público, tal como se advierte de la redacción original del tercer párrafo del artículo 97 constitucional, que establecía lo siguiente:

\begin{abstract}
"Podrá también la Suprema Corte de Justicia de la Nación nombrar Magistrados de Circuito y Jueces de Distrito supernumerarios que auxilien las labores de los tribunales o juzgado donde hubiere recargos de negocios a fin de obtener que la Administración de Justicia sea pronto y expedita; y nombrará alguno o algunos de sus miembros o algún Juez de Distrito o Magistrado de Circuito, o designará uno o varios comisionados especiales, cuando así lo juzgue conveniente o lo pidiere el Ejecutivo Federal, o alguna de las Cámaras de la Unión, o el Gobernador de algún Estado, únicamente para que averigüe la conducta de algún Juez o Magistrado Federal o algún hecho o hechos que constituyan la violación a alguna garantía individual, o la violación del voto público o algún otro delito castigado por la ley federal"'.
\end{abstract}

4. Diario Oficial del 5 de febrero de 1917.

Revista de Ciencias Sociales - Número 62 (2012) - Universidad de Valparáíso - ISSN 0716-7725-Valparáiso, Chile 
Es importante que mencionemos, que de acuerdo a la exposición de motivos de la Constitución General ${ }^{5}$, no se advierte que el contenido del artículo 97 haya sido objeto de debate o cuestionamiento alguno, “ni siquiera un dictamen especial y se aprobó tal como lo presentó el primer jefe, constituyendo una disposición nueva" ${ }^{6}$, situación que hace insustancial que desentrañemos el verdadero sentido de dicha disposición, pues al no haber sido objeto de debate, no se puede señalar de manera clara y objetiva las razones por las que fue creado este medio de defensa de la Ley Fundamental.

A pesar de lo referido, podemos vislumbrar que la intención del constituyente de 1916-1917, era la de dotar a la Suprema Corte, —además del Juicio de Amparo-, de otro mecanismo procesal que le permitiera al Poder Judicial de la Federación, velar por el respeto absoluto de los derechos fundamentales, tal como se aprecia en el mensaje de don Venustiano Carranza ante el constituyente de 1916, en el que enfatizaba respecto al Poder Judicial lo siguiente:

"Otras reformas sobre cuya importancia y trascendencia quiero, señores diputados, llamar vuestra atención, es la que tiende asegurar la completa independencia del Poder Judicial, reforma que, lo mismo que la que ha modificado la duración del cargo de presidente de la República, está revelando claramente la notoria honradez y decidido empeño con el que el Gobierno emanado de la revolución está realizando el programa proclamado en la heroica Veracruz de diciembre de 1914, supuesto que uno de los anhelos más ardientes y más hondamente sentidos por el pueblo mexicano, es el de tener tribunales independientes que hagan efectiva las garantías individuales contra los atentados y excesos de los agentes del poder público y que protejan el goce quieto y pacífico de los derechos civiles de que ha carecido hasta hoy"7.

5. Suprema Corte de Justicia de la Nación: Nuevo Diario de Debates del Congreso Constituyente de 1916-1917. México, 2005, Págs. 2037-2039.

6. Tesis Constitucional con número de registro 815,169, Tomo correspondiente al informe de labores de 1946, Quinta Época, 1946. Pág. 194.

7. TENA RAMÍREZ, Felipe: Leyes Fundamentales de México 1908-1999 (vigésimo segunda edición). Editorial Porrúa, México, 1999. Pág. 763.

Facultad de Derecho y Ciencias Sociales - Universidad de Valparaíso - Chile 
En la etapa correspondiente a la Quinta Época, el Pleno de la Suprema Corte de Justicia, sostuvo que, "El constituyente quiso principiar a dar forma judicial a las contiendas electorales para eliminar sus vicios y la violaciones de las garantías individuales o de las leyes penales federales, acudiendo al sólido y sereno prestigio de la autoridad del Poder Judicial de la Federación" fundamentales del hombre fueran desconocidos por los gobernantes.

En el ámbito doctrinal, los distinguidos juristas Tena Ramírez y Burgoa Orihuela, consideran muy desafortunada la facultad en materia política otorgada a la Suprema Corte en 1917, tal como se aprecia en sus opiniones.

Así tenemos, que Felipe Tena Ramírez sostiene:

"En cuando a la posibilidad de que la Corte intervenga en el sufragio para pugnarlo de sus vicios ancestrales, la opinión pública bien orientada tendrá que renunciar a pedirlo. El fraude electoral que hinca sus raíces en lo más íntimo de nuestra historia, desencadenó en otro tiempo luchas armadas y suscita todavía pasiones violentas, lo poco que el poder central hace para expirar esas raíces, no compensaría el previsible quebranto de su neutralidad, que constituye su razón de ser y única fuerza. Si la Corte interviniera en la política electoral con intención de sanearla, podría contraer la enfermedad, pero no curarla. Con su intención como decía Guizot, "la política no tiene nada que ganar, pero la justicia tiene mucho que perder" .

En este mismo sentido, coincidiendo en términos generales con el maestro, Ignacio Burgoa, afirma:

"Si la corte determinará que se violó el voto público y que en su concepto existe duda sobre la legalidad del proceso de elección de los integrantes del Congreso de la Unión o de Presidente de la Republica, sólo se concretaría a hacer llegar los resultados de la investigación a los órganos competentes para que decidan lo que proceda, es decir, a la

8. Tesis Constitucional con número de registro 815,145, Tomo correspondiente al informe de labores de 1946, Quinta Época, 1946. Pág. 191.

9. TENA RAMÍREZ, Felipe: Derecho Constitucional Mexicano (novena edición). Editorial Porrúa, México, 1968. Pág. 518.

Revista de Ciencias Sociales - Número 62 (2013) - Universidad de Valparáíso - ISSN 0716-7725-Valparaíso, Chile 
Cámara de Senadores o a la de Diputados. Por estas razones, consideramos inútil e ineficaz la facultad investigadora que en ambos casos se inviste al máximo tribunal del país, el cual debe tener injerencia en modo absoluto en materia política" ${ }^{10}$.

\section{a) Causas de la investigación}

Aun cuando dicha facultad podía activarse indistintamente para la investigación de la violación a las garantías individuales o al voto público. En el presente trabajo solo nos ocuparemos del primer supuesto, pues esto nos permite vincularlo y encaminarlo a la reforma en materia de derechos humanos y determinar su viabilidad de haberle concedido dicha facultad ahora a la Comisión Nacional de los Derechos Humanos.

\section{- Violación grave a los derechos humanos}

La violación a los derechos humanos antes garantías individuales es combatible mediante el Juicio de Amparo previsto en los artículos 103 y 107 de la Constitución Política de los Estados Unidos Mexicanos cuyas disposiciones reglamentarias están previstas en la Ley de Amparo. Es el medio de control constitucional como instrumento jurídico por excelencia para contrarrestar los abusos del poder sobre el gobernado.

Ahora bien, en relación al conocimiento de la violación grave de los derechos humanos que motivaban la intervención de la Suprema Corte de Justicia de la Nación, debían ser generalizados, permanentes y reiterados sobre un grupo significativo de la sociedad, de tal manera que, existía incertidumbre jurídica sobre la observancia de la constitución y el respeto a los ahora derechos humanos por parte de determinada autoridad, en este caso se justificaría la intervención de investigar de la Corte, pues de no ser así, se haría nugatorio el estado de derecho que es el pilar para el desarrollo democrático del país.

Además, es pertinente referir que "debe tratarse de hechos cuya autoría sea atribuible a autoridades estatales o municipales; en el caso,

10. BURGOA ORIHUELA, Ignacio: Derecho Constitucional Mexicano. Editorial Porrúa, México, 2002. Pág. 844.

Facultad de Derecho y Ciencias Sociales - Universidad de Valparaíso - Chile 
no importa que las realicen autoridades de hecho o de derecho. (...) Los atribuibles a autoridades deben ser violatoria de las garantías individuales (...) las que se mencionan en los primeros 29 artículos de la constitución" ${ }^{11}$.

Finalmente, es pertinente señalar que, en la actualidad era poco factible que la Suprema Corte de Justicia de la Nación en su papel de un auténtico Tribunal Constitucional, se avoque al estudio de la violación grave y generalizada de los derechos humanos al amparo de esta facultad potestativa, pues es evidente que, la evolución del derecho público en nuestro país, particularmente, la de organismos encargados de velar por el respeto a la dignidad de la mujer y del hombre, como Comisiones de Derechos Humanos, Institutos de Protección de Grupos Marginados, órganos de transparencia, etc., permiten que cualquier actuación de las autoridades estén vigiladas por estos órganos autónomos y descentralizados de las instituciones del poder. De tal manera que, hoy en día, difícilmente escapa una arbitrariedad al lazo de la justicia, es por ello que el Poder Legislativo determinó suprimir dicha facultad de investigación del artículo 97, para trasladarlo al 102 Apartado B de nuestra Ley Fundamental.

\section{b) Quien realiza la investigación}

\begin{tabular}{|c|l|}
\hline \multicolumn{1}{|c|}{ ANTES DE LA REFORMA } & \multicolumn{1}{|c|}{ DESPUÉS DE LA REFORMA } \\
\hline $\begin{array}{l}\text { La investigación podía ser realizada, por } \\
\text { el nombramiento de la propia Corte, }\end{array}$ & $\begin{array}{l}\text { Ahora la investigación corre a cargo de } \\
\text { por: }\end{array}$ \\
$\begin{array}{l}\text { Humanos a través de su Consejo } \\
\text { a) sus propios miembros; } \\
\text { b) algún Juez de Distrito o } \\
\text { Magistrado de algún Tribunal } \\
\text { Colegiado, o uno o varios comisio- } \\
\text { nados especiales. }\end{array}$ \\
\hline
\end{tabular}

11. ARTEAGA NAVA, Elisúr: Derecho Constitucional (segunda edición). Editorial Oxford, México, 2004. Pág. 856.

Revista de Ciencias Sociales - Número 62 (2013) - Universidad de Valparáíso - ISSN 0716-7725-Valparaíso, Chile 
c) Quien puede pedir la investigación

\begin{tabular}{|l|l|}
\hline ANTES DE LA REFORMA & DESPUÉS DE LA REFORMA \\
\hline a) El Ejecutivo Federal; & a) El Ejecutivo Federal; \\
b) Alguna de las Cámaras del & b) Alguna de las Cámaras del \\
& Congreso de la Unión; \\
c) Longreso de la Unión; & c) Los gobernadores de los Estados \\
y el Jefe de Gobierno del Distrito & y el Jefe de Gobierno del Distrito \\
Federal, o & Federal, o \\
d) Motu propio ${ }^{12}$ & d) Las legislaturas de las entidades \\
& federativas. \\
\hline
\end{tabular}

Es oportuno señalar, que cuando la Suprema Corte de Justicia hacía uso de la facultad de indagación de hechos por presuntas violaciones a las garantías individuales o al voto público, ésta actuaba como un órgano de instrucción, y no propiamente en el carácter de órgano terminal de decisión o de ejecución, por lo que eminentemente se desprende de su naturaleza jurisdiccional para ubicarse en funciones meramente administrativas, es decir, instaurador de un procedimiento de investigación y no de proceso judicial” ${ }^{13}$.

\section{d) Resultados de la investigación}

Dependiendo de la autoridad que designaron los Ministros de Suprema Corte, ya sea un Juez de Distrito, un Magistrado de Colegiado o algún comisionado, el resultado de la investigación debía presentarse en primer término al Presidente de la Corte para que este oportunamente la pudiera presentar al Pleno, en donde se determinaba a qué autoridad debían remitir los resultados que arrojó la investigación en términos de las atribuciones que la constitución otorga a diversas institucional del gobierno.

12. FERRER MAC-GREGOR, Eduardo (coord.): Derecho Procesal Constitucional (5a. ed.). Porrúa, México 2006, t. II, pág. 1273.

13. CARPIZO, Jorge: Estudios Constitucionales (octava edición). Editorial Porrúa, México 2003. Pág. 65.

Facultad de Derecho y Ciencias Sociales - Universidad de Valparaíso - Chile 
Es claro, que si la investigación fue motivada por la violación grave a las garantías individuales previstas en la ley suprema a favor de los gobernados, los resultados de la investigación se harían llegar al Presidente de la Republica para que por conducto se envíe al Procurador General de la República y este determine si con motivo de la investigación se advierte la comisión de algún o algunos ilícitos, y por otra parte, al Congreso General para efectos del juicio político o la investigación correspondiente.

Tratándose de violaciones a los derechos políticos de los ciudadanos en la participación de la renovación de los poderes, si efectivamente, se determinaba la existencia de indicios para considerar la ilegalidad de las etapas del proceso electoral, esta se enviaba a los órganos competentes, es decir, Instituto Federal Electoral o Tribunal Electoral del Poder Judicial de la Federación, según sea el caso.

\section{Los aspectos positivos de la reforma al artículo 102, apartado b, de la Constitución}

Una vez abordados los antecedentes, me ocupo en este documento únicamente de un aspecto del "paquete de reformas": la supresión de la facultad de investigación que el artículo 97, segundo párrafo, de la Constitución le otorgaba a la Suprema Corte de Justicia de la Nación para transferírsela a la Comisión Nacional de los Derechos Humanos, en su artículo 102, Apartado B.

Dentro de las sendas reformas enviadas al Congreso Federal, he de resaltar los aspectos positivos de la reforma al artículo 102 de la Constitución:

"Si las recomendaciones no son aceptadas o cumplidas por las autoridades o servidores públicos, éstos deben fundar, motivar y hacer pública su negativa".

Considero que este punto es el más importante de las reformas al citado artículo, en virtud que existe un grave problema de recomendaciones que no son aceptadas, cumplidas a medias o, de plano, no cumplidas.

Para solucionar este problema, esta disposición ayudaría en gran manera sin duda alguna, pero no en forma total.

Revista de Ciencias Sociales - Número 62 (2013) - Universidad de Valparáíso - ISSN 0716-7725-Valparaíso, Chile 
"Se otorga a las Comisiones de Derechos Humanos competencia en asuntos laborales".

El Dr. Jorge Carpizo consideró que, desde una perspectiva, en realidad no se les está atribuyendo una nueva facultad, y señala el porqué:

“...Si el asunto laboral es de carácter administrativo expedido por una autoridad, las Comisiones poseen dicha facultad, de acuerdo con el texto constitucional; por ejemplo, la negación de un registro sindical, que es un acto totalmente administrativo de una autoridad laboral.

Si el asunto laboral es de carácter jurisdiccional; es decir, si se encuentra en el conocimiento de una junta de conciliación y arbitraje o ya existe laudo, entonces las comisiones son y continuarán siendo incompetentes por tratarse un asunto jurisdiccional.

Cuando la Constitución excluye del conocimiento de las Comisiones los asuntos laborales no se refiere a actos administrativos de autoridades o funcionarios, ni a los jurisdiccionales que se encuentran excluidos por su propia naturaleza, sino a los actos laborales entre particulares como puede ser un despido sin causa justificada, por la razón de que las Comisiones no pueden ser un "sanalotodo", que se encuentren inundadas de casos que les imposibiliten resolver, cuando su propia naturaleza lo implica, de manera ágil y rápida. Si no es así, el ombudsman pierde parte de su razón de ser"'14.

Asimismo, debe tener en cuenta que ya existen las Procuradurías del Trabajo que son también una especie de ombudsman. En nuestro país los ombudsman, como en muchos otros, se especializan. Piénsese en la Procuraduría Federal del Consumidor, en la Procuraduría Agraria y en la Comisión Nacional de Arbitraje Médico.

a) Otro aspecto de la reforma expresa que: "Las Constituciones de los Estados y el Estatuto de Gobierno del Distrito Federal establecerán y garantizarán la autonomía de los organismos de protección de los derechos humanos”.

14. CARPIZO, Jorge: "Es acertada la probable transferencia de la función de investigación de la Suprema Corte a la Comisión Nacional de los Derechos Humanos”. En: Carbonell, Miguel y Salazar, Pedro, (coords.): La reforma constitucional de derechos humanos: un nuevo paradigma, México, IIJ-UNAM, 2011. Pág. 324.

Facultad de Derecho y Ciencias Sociales - Universidad de Valparaíso - Chile 
Este también es un aspecto de especial importancia, debido a que muchas - no todas - comisiones estatales, se encuentran controladas por los gobernadores. Si las Comisiones no gozan de independencia de poco sirven.

Su naturaleza es de órgano constitucional autónomo y ésta debe ser garantizada. La reforma constitucional aludida desde su proyecto hizo bien en retirar esa naturaleza.

Sin embargo, considero que si las constituciones locales no precisan esta situación, poco servirá tal alusión en la Constitución Federal.

En ese sentido la Constitución Política del Estado de Tamaulipas sí lo precisa en su artículo 126 al establecer que: “...el organismo a que se refiere el artículo 58; fracción XVIII, de esta Constitución se denominará Comisión de Derechos Humanos del Estado de Tamaulipas. Será un organismo público, autónomo e independiente, con personalidad jurídica y patrimonio propios que tendrá por objeto la protección de los derechos humanos que otorga el orden público mexicano...".

A pesar de lo anterior, considero que es deseable y necesario ser más específicos en el sentido de que se deben contemplar situaciones como, presupuesto, elección del titular, remuneración, inamovilidad, o equiparar estos aspectos al Tribunal Superior de Justicia y sus Magistrados.

Sin embargo habrá que ver qué acontece en la realidad.

b) Otro punto sobresaliente es el relativo al nombre del titular y de los integrantes del Consejo Consultivo de la Comisión Nacional de los Derechos Humanos, y de los titulares de las comisiones locales se realicen a través de un procedimiento de consulta pública, que deberá ser transparente, en los términos y condiciones que determine la ley.

Me parece acertada la decisión, sobre todo por el aspecto democrático, el cambio que está viviendo nuestro país en relación al Sistema Político, requiere la participación de la ciudadanía, en la toma de decisiones.

Revista de Ciencias Sociales - Número 62 (2013) - Universidad de Valparáíso - ISSN 0716-7725-Valparaíso, Chile 


\section{Conveniencia de suprimirle la facultad de investigación a la Suprema Corte de Justicia de la Nación}

Desde la edición del Libro Blanco de la Reforma Judicial en Octubre de 2006, ya se venía contemplando esta modificación, y es que como parte del debate en torno a cómo se debía proseguir el proceso de reforma judicial en torno a la Suprema Corte, hay quienes desde ese entonces apuntaban que para consolidar a ésta como tribunal constitucional y debido a su vocación, debería despojársele de esta facultad pues carece de la infraestructura necesaria para ejercitarla; facultad excepcionalmente utilizada y cuyos efectos o resultados tienden a diluirse, con lo que se pone en entredicho no sólo la utilidad del mecanismo, sino a la propia institución. Sin embargo hay quienes se inclinaban por mantener la facultad de investigación pero aconsejaban que se regulara tanto por lo que hacía a la procedencia, como a los efectos de los dictámenes que se llegarían a emitir al ejercerla ${ }^{15}$.

$\mathrm{Y}$ es que la escasa aplicación del mencionado procedimiento indagatorio antes en poder de la Suprema Corte de Justicia, actualmente limitado a la violación grave de derechos humanos, aconsejaba la desaparición de este procedimiento, ya que los motivos que se expresaron en la exposición del Proyecto de Constitución presentado el $1^{\circ}$ de diciembre de 1916 por Don Venustiano Carranza al Congreso Constituyente de Querétaro no tienen sustento en nuestro época, ya que en la hipótesis de investigación que se confirieron a la Suprema Corte por el Constituyente de Querétaro, incluyendo la única que conserva, cuentan en la actualidad con organismos que pueden realizar las investigaciones objetivas que en su época consideró necesarias el citado Constituyente ${ }^{16}$.

En relación con lo anterior, en las conclusiones del Libro Blanco de la Reforma Judicial, se proponen 33 acciones para reformar la justicia

15. CABALlero JUÁREZ, José Antonio et al: Libro Blanco de la Reforma

Judicial. Una agenda para la Justicia en México. Suprema Corte de Justicia de la Nación, México, 2006. Pág. 94.

16. FIX ZAMUDIO, Héctor: ob. cit. Pág. 287.

Facultad de Derecho y Ciencias Sociales - Universidad de Valparaíso - Chile 
en México, y en la acción 20 se sostiene: fortalecer a la Suprema Corte de Justicia como tribunal constitucional, en cuyo segundo párrafo ${ }^{17}$ se afirma en lo pertinente:

(...) Por las razones expuestas en el cuerpo de este Libro Blanco se recomienda que el Constituyente Permanente proceda en el mediano plazo a la eliminación de las facultades de investigación establecidas en el artículo 97 de la Constitución. Ello por considerar que estas facultades no corresponden al diseño de un tribunal constitucional. En el caso de que esa recomendación no se considere adecuada, el Congreso de la Unión deberá en el mismo plazo reglamentar dichas facultades para precisar tanto sus causales de procedencia como sus efectos.

De lo anterior puede advertirse que la Suprema Corte ya no deseaba contar con dicha facultad, en virtud de que cada que realizaba alguna investigación la imagen de la misma se veía deteriorada.

\section{Las últimas y recientes investigaciones que realizó la Suprema Corte de Justicia de la Nación antes de la reforma constitucional}

En virtud de que el Congreso Federal no tomó en cuenta la propuesta señalada en supra líneas, ésta decidió reglamentar la disposición del segundo párrafo del artículo 97 de la Ley Suprema en cuanto a sus facultades de investigación, en particular las relativas a “(...) a algún hecho o hechos que constituyan una grave violación a alguna garantía individual (...)” por conducto del Acuerdo General núm. 16/2007, publicado en el Diario Oficial de la Federación del 22 de agosto del mismo año que estableció la legitimación, la procedencia y la tramitación de la mencionada facultad de investigación.

En base al acuerdo anterior, las mesas directivas de las cámaras de Senadores y de Diputados se dirigieron a la Suprema Corte para que este alto Tribunal ejerciera su facultad de investigación del segundo párrafo del artículo 97 constitucional, para indagar sobre los hechos que pudieran configurar un agravio y violación de las entonces garantías

17. CABALLERO JUÁREZ, José Antonio: ob. cit. Pág. 402.

Revista de Ciencias Sociales - Número 62 (2013) - Universidad de Valparáíso - ISSN 0716-7725-Valparaíso, Chile 
individuales de la periodista Lydia Cacho, en las cuales pudieran estar vinculados tanto el Gobernador como la Procuraduría General de Justicia del Estado de Puebla. Este caso fue muy particular, en el sentido de que se trataba de un caso individual, y dicha individualidad no estaba consagrada en la disposición constitucional. Después de las pesquisas realizadas por dos magistrados de circuito, que se consideraron insuficientes, se designó al entonces Ministro ahora Presidente de la Suprema Corte Juan Silva Meza, asistido por dos magistrados de circuito, quienes formularon nuevas conclusiones, y se encargó a dicho señor ministro para elaborar la ponencia respectiva.

El 29 de noviembre de 2007 se realizó la discusión pública de este asunto, y después de un amplio debate se desestimó el proyecto de dictamen presentado por el Ministro Silva Meza, en el sentido de que existían evidencias que demostraban que altos funcionarios del estado de Puebla habían infringido los derechos humanos de la periodista Lydia Cacho; el principal argumento para desechar el proyecto fue el de que la única evidencia presentada, además de las declaraciones de la denunciante, era una conversación telefónica privada no colaborada por otras fuentes, y que no podía aceptarse en virtud de que la grabación aludida no fue el resultado de una intervención autorizada por orden judicial $^{18}$.

En 2009 la Suprema Corte empezó la discusión sobre una investigación realizada, también a petición del Congreso de la Unión, sobre acontecimientos que ocurrieron en los municipios de Texcoco y San Salvador Atenco del Estado de México, ocurridos el 3 y 4 de mayo de 2006, en los cuales se produjeron enfrentamientos entre las fuerzas policiacas tanto federales como de dicha entidad federativa, para desalojar a un grupo de personas que durante bastante tiempo habían suplantado ilegalmente y por la fuerza a las autoridades municipales.

Otro caso que ha investigado la Corte es el relativo a los graves acontecimientos que se produjeron en el estado de Oaxaca durante varios meses de manifestaciones y violencia en 2007, en varios municipios y la capital del estado, provocados por los enfrentamientos entre la Sección XII del Sindicato Nacional de los Trabajadores de la

18. FIX ZAMUDIO, Héctor: ob. cit. Pág. 289.

Facultad de Derecho y Ciencias Sociales - Universidad de Valparaíso - Chile 
Educación y la llamada Asamblea Popular de los Pueblos de Oaxaca (APPO), dichos enfrentamientos hicieron necesaria la intervención de la Policía Federal Preventiva para terminar con dicho conflicto.

Y sin duda alguna el que más conmovió a la sociedad mexicana fue el suscitado en la ciudad de Hermosillo, Sonora, provocado por un incendio de un local inadecuado que había sido subrogado por el Instituto Mexicano del Seguro Social a un grupo de particulares para instalar una guardería infantil, y que tuvo un saldo trágico de 49 infantes fallecidos y otros más resultaron con quemaduras graves. Por esta trágica situación los familiares afectados solicitaron a la Suprema Corte que realizara una investigación sobre estos hechos. Esta petición de la facultad de investigación que lleva el núm. 1/2009 fue hecha suya por el ministro Sergio A. Valls Hernández, por lo que se turnó al ministro Sergio Salvador Aguirre Anguiano, quien presentó un proyecto en el sentido de que la Corte no había de ejercer la propia facultad de investigación, dicho proyecto se discutió el 6 de agosto de 2009, y se votó en el sentido de admitir la petición.

El dictamen del respectivo asunto elaborado por el ministro Arturo Zaldívar Lelo de Larrea, en el cual determinó que existe responsabilidad para las principales autoridades del Instituto Mexicano del Seguro Social, señalando el Considerando Séptimo del dictamen lo siguiente: "Juan Francisco Molinar Horcasitas fue Director General del Instituto Mexicano del Seguro Social del primero de diciembre de dos mil seis al tres de marzo de dos mil nueve por lo que le es atribuible el desorden generalizado en el otorgamiento, operación y supervisión del servicio de guarderías operado bajo el sistema de subrogación, que propiciaron las condiciones para la tragedia ocurrida en la guardería ABC", y por lo que respecta a Daniel Karam Toumeh señalo lo siguiente: "que desde el tres de marzo del año dos mil nueve a la fecha se desempeña como Director General del Instituto Mexicano del Seguro Social, debido a que asumió todas las atribuciones y responsabilidades derivadas de la dirección de dicho Instituto. Este funcionario también es responsable de la gestión de los eventos posteriores al incendio y de la atención médica que se ha brindado a las víctimas"19.

19. Dictamen de la Facultad de Investigación 1/2009. Caso Guardería ABC elaborado por el Señor Ministro Arturo Zaldívar Lelo de Larrea.

Revista de Ciencias Sociales - Número 62 (2013) - Universidad de Valparáíso - ISSN 0716-7725-Valparaíso, Chile 
También se responsabilizó al entonces Gobernador del Estado, Eduardo Bours Castelo al cual, le son atribuibles las omisiones que provocaron la grave falla del Sistema Estatal de Protección Civil, el cual fue inefectivo para detectar la acumulación de riesgos que rodeaban a la Guardería ABC y la bomba de tiempo que representaba la bodega adyacente.

Con lo anterior nos damos cuenta, que sí existió una responsabilidad para las principales autoridades, sin embargo como el dictamen de la Suprema Corte de Justicia de la Nación, pero no fueron castigadas en virtud de que la Corte sólo investiga, realmente no está aplicando ninguna ley ${ }^{20}$.

En todos y cada uno de los casos anteriores nuestro máximo Tribunal ha actuado en base a los cuatro principios rectores fundamentales de la ética judicial (independencia, imparcialidad, objetividad y profesionalismo) ${ }^{21}$, sin embargo, el prestigio de la Suprema Corte ha sido cuestionado por todos los grupos que conforman nuestra sociedad.

\section{La primera investigación por violaciones graves a los derechos humanos realizada por la Comisión Nacional de los Derechos Humanos: el caso Ayotzinapa}

Por primera vez, en los términos del último párrafo del artículo 102 de la Constitución Política de los Estados Unidos Mexicanos, reformado el 10 de junio de 2011, la Comisión Nacional ejerció esta nueva atribución que le otorgó el poder legislativo.

Los hechos que investigó la Comisión Nacional de los Derechos Humanos, sucedieron el 12 de diciembre de 2011, cuando servidores públicos de la Secretaría de Seguridad Pública federal, así como de la Policía Ministerial, adscritos a la Procuraduría General de Justicia y de la Policía Estatal de la Secretaría de Seguridad Pública y Protección Civil, ambas del estado de Guerrero realizaron disparos de arma de

20. FERRER MAC-GREGOR, Eduardo (coord.): ob. cit. Pág. 1276.

21. Código de Ética del Poder Judicial de la Federación.

Facultad de Derecho y Ciencias Sociales - Universidad de Valparaíso - Chile 
fuego contra 52 personas y un grupo indeterminado que se encontraba en esa fecha en una manifestación de estudiantes de la Normal Rural "Raúl Isidro Burgos" de Ayotzinapa; la manifestación tenía como objetivo expresarse por la negativa del Titular del Poder Ejecutivo del estado de Guerrero para recibirlos en audiencia para exigirle mejores condiciones educativas en la Entidad.

En esos sucesos tres personas perdieron la vida, dos estudiantes por lesiones de proyectil de armas de fuego, además del empleado de una gasolinera, a consecuencia de las quemaduras que sufrió al intentar sofocar el fuego en una bomba de combustible.

Así mismo se acreditó que un estudiante de 19 años fue víctima de tortura y acusado indebidamente de haber disparado un arma de fuego denominada "cuerno de chivo".

En esta ocasión la Comisión Nacional de los Derechos Humanos contó con elementos que permitieron evidenciar violaciones graves a la libertad de reunión y como consecuencia de ello a los derechos a la vida, seguridad e integridad personal, legalidad, seguridad jurídica, libertad personal y trato digno, explicó el Doctor Plascencia Villanueva titular del Organismo Público Autónomo.

Además se observaron trasgresiones a los derechos a la verdad e información y a todos aquellos derechos que el orden jurídico mexicano reconoce a las personas en su calidad de víctimas del delito y del abuso del poder.

La Comisión Nacional observó que con motivo de los hechos, elementos de diferentes corporaciones policiales realizaron la detención arbitraria de 42 personas, 24 de ellas sometidas a golpes de palos y toletes. En este grupo se hallaban cuatro menores de edad y una mujer.

En razón de dicha investigación, la Comisión Nacional de los Derechos Humanos formuló 30 puntos recomendatorios específicos: 13 de manera conjunta a la Secretaría de Seguridad Pública federal y al gobernador del estado de Guerrero; cuatro a la Secretaría de Seguridad Pública federal; 11 al gobierno estatal, y dos a la presidencia de la mesa directiva de la LIX Legislatura del Congreso de la entidad.

Con motivo de este lamentable incidente el 13 de diciembre de 2011, el Gobernador del Estado de Guerrero informó que fueron separados de sus cargos el Procurador General de Justicia, el

Revista de Ciencias Sociales - Número 62 (2013) - Universidad de Valparáíso - ISSN 0716-7725-Valparaíso, Chile 
Subprocurador de Justicia y el Secretario de Seguridad Pública de dicha Entidad.

Posteriormente y con motivo de las recomendaciones emitidas por la Comisión Nacional de los Derechos Humanos, el ahora ex subprocurador de Justicia Alejandro Hernández Paz y Puente y la agente del Ministerio Público Investigador, Gloria Rocío Méndez Cruz, fueron detenidos por agentes federales y recluidos en el penal capitalino.

Ambos ex funcionarios de la Procuraduría General de Justicia fueron consignados ante el Juzgado Primero de Distrito por el delito de "encubrimiento por favorecimiento", relacionado con la liberación de un normalista que supuestamente portaba un rifle AK-47 durante el desalojo realizado el 12 de diciembre de 2011 por agentes federales y estatales al sur de esta capital, donde varios estudiantes fueron asesinados a tiros.

Así mismo existen órdenes de aprehensión contra el también subprocurador de Justicia, César de los Santos Mendoza, así como para el ex director de Averiguaciones Previas, José Vélez Zapata; la ex fiscal regional, María Severiana Peña Flores, y la agente del Ministerio Público del fuero común Magdalena de Jesús Cruz, por incurrir presuntamente en el mismo delito de "encubrimiento por favorecimiento".

Cabe hacer mención que además de los servidores públicos mencionados anteriormente, sólo el ex Procurador de Justicia Alberto López Rosas enfrenta proceso penal por los delitos de "encubrimiento" y "contra la administración de la justicia, en su modalidad de liberar a presuntos delincuentes”, debido a que la Procuraduría General de la República lo acusa de haber ordenado poner en libertad a 24 personas detenidas durante el desalojo del 12 de diciembre.

Como podemos observar, con motivo de esta primera investigación realizada por la Comisión Nacional de los Derechos Humanos, sus recomendaciones han impulsado el inicio de diversos procesos penales en contra de servidores públicos del Estado de Guerrero que tuvieron intervención ya sea por acción u omisión durante la represión de los estudiantes normalistas, sin embargo dichos procedimientos que se encuentran en manos de la autoridad judicial son por delitos diversos a los señalados por el Ombudsman mexicano en sus recomendaciones, es decir, los servidores públicos no fueron

Facultad de Derecho y Ciencias Sociales - Universidad de Valparaíso - Chile 
puestos a disposición de la autoridad judicial por haber vulnerado los derechos fundamentales de los estudiantes, sino por haber cometido delitos procedimentales cometidos en razón de las investigaciones realizadas por la Procuraduría General de Justicia del Estado de Guerrero por los hechos ocurridos el 12 de diciembre de 2011 en Ayotzinapa.

\section{Conclusiones}

Tal y como se mencionó en el apartado número VI, los motivos que se expresaron en la exposición del Proyecto de Constitución de 1917, para otorgarle a la Suprema Corte la facultad de investigación, ya no tienen sustento en nuestra época, además de carecer de sentido en virtud de la creación de las comisiones de derechos humanos, tanto la nacional como la de las entidades federativas, es por ello que considero acertada la decisión del Congreso Federal, de suprimirle dicha facultad a la Suprema Corte, en virtud de que no resultaba compatible con las funciones de un tribunal constitucional como lo es nuestro máximo Tribunal.

Aunado a que la multicitada facultad investigadora, colocaba a la Suprema Corte en la indigna tesitura de ser contradicha o menospreciada por autoridades administrativas o judiciales que en lo tocante a la verdadera función jurisdiccional están bajo su potestad jurídica ${ }^{22}$.

En palabras de Don Ignacio Burgoa, se antoja un señuelo para que dicho alto Tribunal cayera en la trampa del desprestigio y del ridículo, rebajándolo a la condición de agente de averiguaciones políticas y penales y desplazándolo del augusto sitial en que la doctrina y la Constitución lo han colocado ${ }^{23}$.

Por estas razones, se consideraba inútil e ineficaz la extinta facultad investigadora con que se enviste al máximo tribunal del país, el cual no debe tener injerencia por modo absoluto en materia política ${ }^{24}$.

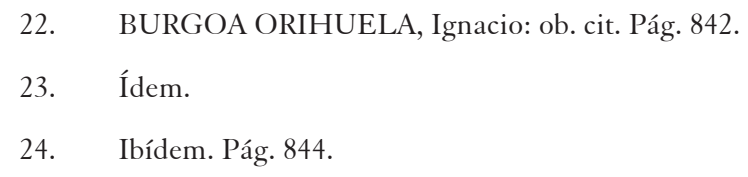


Con la primera investigación realizada por la Comisión Nacional de los Derechos Humanos, quedó de manifiesto que sus recomendaciones a pesar de no ser de carácter vinculatorio, sí tienen la fuerza necesaria para iniciar un proceso penal a todo aquel servidor público que vulnere con motivo de su actividad gubernamental cualquier derecho fundamental, si bien en este primer caso los servidores públicos están siendo sancionados por delitos diversos, también lo es, que dicho incidente no ha quedado en el escritorio de la autoridad investigadora como sucedía antes de junio de 2011, cuando la Suprema Corte de Justicia de la Nación investigaba, acreditaba la vulneración a las entonces denominadas garantías individuales ahora derechos humanos cometida por algún servidor público, pero no podía sancionar porque sus resoluciones las emitía a través de un "informe" sin fuerza jurisdiccional alguna, en ese sentido no cumplía con lo señalado en la Constitución Política de los Estados Unidos Mexicanos que señala que en el principio de división de poderes en el sistema político mexicano el Poder Judicial será el encargado de la imposición de las penas, y ahora con la reasignación de dicha facultad de investigación vemos que se ha dado un gran paso en México al otorgar el legislador una legislación proteccionista en pro de los derechos humanos.

\section{Bibliografía}

ARTEAGA NAVA, Elisur, Derecho Constitucional, segunda edición, editorial Oxford, México, 2004.

BURGOA ORIHUELA, Ignacio, Derecho Constitucional Mexicano, $15^{\mathrm{a}}$, ed., editorial Porrúa, México, 2002.

CABALLERO JUÁREZ, José Antonio et al., Libro Blanco de la Reforma Judicial. Una agenda para la Justicia en México, México, Suprema

Corte de Justicia de la Nación, 2006.

CARBONELL, Miguel y SALAZAR, Pedro, (coords.), La reforma constitucional de derechos humanos: un nuevo paradigma, México, 2011, IIJ-UNAM.

CARPIZO, Jorge, Estudios Constitucionales, octava edición, editorial porrúa, México 2003.

Facultad de Derecho y Ciencias Sociales - Universidad de Valparaíso - Chile 
FERRER MAC-GREGOR, Eduardo (coord.), Derecho Procesal Constitucional, quinta edición, editorial Porrúa, México 2006, t. II.

FIX ZAMUDIO, Héctor, Estudio de la Defensa de la Constitución en el Ordenamiento Mexicano, segunda edición, editorial Porrúa, México, 2005.

y otro, Derecho Constitucional Mexicano y Comparado, quinta edición, editorial Porrúa, México, 2007.

TENA RAMÍREZ, Felipe, Derecho Constitucional Mexicano, novena edición, editorial Porrúa, México, 1968.

Leyes Fundamentales de México 1908-1999, vigésimo segunda edición, editorial Porrúa, México, 1999. 